\title{
COMPREENDENDO O SIGNIFICADO DA GESTAÇÃO PARA GRÁVIDAS DIABÉTICAS
}

\author{
Lucía Silva \\ Renata Cerqueira Santos ${ }^{2}$ \\ Cristina Maria Garcia de Lima Parada ${ }^{3}$
}

Silva L, Santos RC, Parada CMGL. Compreendendo o significado da gestação para grávidas diabéticas. Rev Latino-am Enfermagem 2004 novembro-dezembro; 12(6):899-904.

Este estudo qualitativo teve por objetivo compreender o significado da gestação para grávidas diabéticas. Utilizamos entrevista semi-estruturada e, para análise dos dados, construímos o Discurso do Sujeito Coletivo, a partir da identificação das Idéias Centrais: "felicidade frente a uma gravidez desejada" e "preocupação com a gravidez e renúncia"; "minha gravidez foi planejada" e "meu plano era outro"; "sinto o que mulheres grávidas sentem" e "tive muitos problemas na gravidez"; "um filho é tudo o que ele queria" e "ele não teve aquela emoção que nem mulher"; "eu estou controlando, fazendo tudo o que o médico diz" e "eu tô tentando fazer dieta, mas é difícil". As idéias centrais identificadas evidenciam que, também entre as gestantes diabéticas estudadas, planejar e desejar a gravidez e contar com o apoio da família e/ou companheiro foram essenciais para que o tratamento fosse enfrentado de forma tranqüila, e a gravidez fosse vivida de forma prazerosa.

DESCRITORES: complicações na gravidez; gravidez de alto risco; pesquisa qualitativa

\section{UNDERSTANDING THE MEANING OF PREGNANCY FOR PREGNANT DIABETIC WOMEN}

This qualitative study intends to understand the meaning of pregnancy for diabetic women. Semi-structured interviews were carried out and data were analyzed by means of the Collective Subject Discourse, identifying the following central ideas: "happiness about a desired pregnancy", "preoccupation with pregnancy and renouncement", "my pregnancy was planned", "I had other plans", "I feel what pregnant women feel", "I had many problems during pregnancy", "a child was everything that he wanted", "he didn't feel the same emotions as a woman", "I am controlling, doing everything the doctor says", "I am trying to follow a diet, but it is hard". These central ideas demonstrate that, among the diabetic pregnant women, planning and wanting the pregnancy and counting on the support of the family and/or companion were also essential for the treatment to be faced naturally and for the pregnancy to be experienced in a pleasant way.

DESCRIPTORS: pregnancy complications; pregnancy- high risk; qualitative research

\section{COMPRENDIENDO EL SIGNIFICADO DEL EMBARAZO PARA LAS MUJERES DIABÉTICAS EMBARAZADAS}

Este estudio cualitativo tuvo por objetivo comprender el significado del embarazo para las mujeres diabéticas embarazadas. Utilizamos la entrevista semi estructurada y, para el análisis de los datos, construimos el Discurso del Sujeto Colectivo tras la identificación de las ideas centrales: "felicidad delante de un embarazo planeado", "preocupación con el embarazo y renuncia", "mi embarazo fue planeado", "mi plan era otro", "siento lo que las embarazadas sienten", "tuve muchos problemas en el embarazo", "un niño era todo lo que él quería", "él no tiene aquella emoción como la mujer", "estoy cuidándome, haciendo todo lo que el médico dijo", "estoy intentando hacer dieta, pero es difícil". Así, destacamos que también entre las mujeres diabéticas embarazadas estudiadas, planear y desear el embarazo y tener el apoyo de la familia o pareja fueran esenciales para que ese acontecimiento pudiese ser vivido de forma agradable.

DESCRIPTORES: complicaciones del embarazo; embarazo de alto riesgo; investigación cualitativa

\footnotetext{
${ }^{1}$ Enfermeira do Programa de Residência em Saúde da Família da Faculdade de Medicina de Botucatu, e-mail: lucia_funes@yahoo.com.br; ${ }^{2}$ Enfermeira do Programa de Residência em Clínica Médica do Hospital de Base do Distrito Federal, renacsan@yahoo.com.br; ${ }^{3}$ Professor Assistente Doutor da Faculdade de Medicina de Botucatu, e-mail: cparada@fmb.unesp.br
} 
INTRODUÇÃO

A importância do estudo das gestações de risco decorre do fato de elas relacionarem-se com uma maior morbi-mortalidade materna e perinatal. Uma vez identificadas, algumas condições de risco podem ser tratadas e eliminadas, enquanto outras podem ser controladas, diminuindo seu impacto na gravidez. Em outras circunstâncias, ainda, os profissionais de saúde podem ser alertados para observar, com maior rigor, os sinais precoces de complicações, iniciando o tratamento imediatamente.

A associação entre diabetes e gravidez é considerada condição de risco. Trata-se de doença com início insidioso, difícil controle glicêmico e que pode repercutir negativamente sobre a saúde materna e do feto $^{(1)}$. Contudo, a disponibilidade de insulina exógena vem mudando o prognóstico materno e perinatal: a mortalidade perinatal caiu de $65 \%$ (em 1920) para os atuais 2 a $4 \%$, na maioria dos centros terciários ${ }^{(2)}$.

Dentre as possíveis intercorrências na gestação de mulheres diabéticas estão o hiperinsulinismo fetal, as malformações congênitas, a síndrome do desconforto respiratório, a hipoglicemia neonatal, a hipoxemia crônica, a asfixia e o óbito fetal ${ }^{(1-3)}$. Até mesmo com um controle glicêmico adequado, mantido durante a gestação, cerca de 20 a 30\% dos recém-nascidos de mães diabéticas nascem com peso excessivo ${ }^{(3)}$.

Em relação à mãe, quando não há tratamento adequado da doença na gravidez, há maior possibilidade de ocorrência de bacteriúria assintomática, pré-eclâmpsia e morte materna, quando comparamos as gestantes diabéticas com as normais ${ }^{(1)}$.

Como a hiperglicemia da gestante é, em geral, a responsável pela morbidade materna e fetal, o impacto do diabetes na gravidez acaba dependendo do controle glicêmico $^{(1-4)}$.

A possibilidade de ocorrerem intercorrências tanto para as mães quanto para os bebês, a necessidade de um regime alimentar e de internações constantes durante a gravidez, podem gerar angústia para a gestante diabética e sua família. Por outro lado, conhecer como essas gestantes encaram sua gravidez pode auxiliar os profissionais e serviços de saúde na abordagem educativa, essencial para o controle glicêmico e êxito da gestação.

Com a finalidade de contribuir com a assistência prestada a esse grupo de mulheres é que nos propusemos a realizar o presente estudo, cujo objetivo foi compreender o significado da gestação para as grávidas diabéticas.

\section{METODOLOGIA}

O referencial teórico-metodológico

Optamos, no presente estudo, por utilizar a metodologia qualitativa, definida como aquela que se preocupa com um nível de realidade que não pode ser quantificado, trabalhando com o universo de significados, motivos, aspirações, crenças, valores e atitudes que, por sua vez, correspondem a um espaço mais profundo das relações, dos processos e dos fenômenos que não podem ser reduzidos à operacionalização de variáveis ${ }^{(5)}$.

Local de realização do estudo

O estudo foi realizado no Hospital das Clínicas da Faculdade de Medicina de Botucatu - UNESP, pois esse hospital oferece assistência pré-natal e ao parto para gestantes diabéticas. Tal serviço tem capacidade de 28 leitos de obstetrícia, dos quais 12 são destinados ao alojamento conjunto, 3 ao isolamento e 13 a gestantes com patologias obstétricas, incluindo as diabéticas e a puérperas que não ficarão em alojamento conjunto. Possui, também, 3 leitos para pré-parto.

Coleta de dados

Os dados foram colhidos no período de setembro a dezembro de 2000. Foram entrevistadas 22 gestantes com diabetes gestacional ou mellitus - e, como instrumento para coleta de dados, utilizamos a entrevista semiestruturada. Esse tipo de entrevista possibilita, partindo de questões básicas relacionadas aos objetivos do estudo, a ampliação para outras, que surgem à medida que as respostas vão sendo obtidas. Permite, também, que os entrevistados participem da elaboração do conteúdo da pesquisa $^{(6)}$.

Para caracterização dos sujeitos dessa investigação, estudamos variáveis como idade, número de gestações, estado civil, anos de aprovação escolar e ocupação. O roteiro da entrevista incluía, também, questões relativas à gravidez, seu planejamento, sentimentos da entrevistada frente a ela, sua evolução e 
como esta foi vista pelo companheiro.

Tratando-se de estudo qualitativo, a seleção da amostra considerou a variabilidade e qualidade dos sujeitos a serem entrevistados, a fim de que eles pudessem fornecer dados ricos, interessantes e suficientes para compor e reconstituir o pensamento sobre o significado da gravidez para as gestantes diabéticas ${ }^{(7)}$. Interessounos os discursos das gestantes, e o número de entrevistadas dependeu da saturação dos dados colhidos. Intencionalmente, optamos por selecionar gestantes no terceiro trimestre de gravidez, para que elas tivessem vivenciado, por um tempo maior, a gestação associada a diabetes.

Procedimentos éticos

Este estudo foi avaliado e aprovado por Comitê de Ética em Pesquisa e todas gestantes que concordaram em participar dele receberam explicação detalhada sobre sua finalidade e objetivo e assinaram o Termo de Consentimento Livre e Esclarecido para Participação em Estudo Científico.

Análise de dados

As entrevistas gravadas foram transcritas na íntegra. Após a leitura exaustiva, repetida e atenta das informações obtidas, identificamos, primeiramente, as idéias centrais e as expressões-chave que cada uma das gestantes diabéticas apresentou em seus discursos. Em seguida, identificamos as convergências existentes entre as expressões-chave, para darem surgimento ao Discurso do Sujeito Coletivo (DSC) referente a cada uma das idéias centrais previamente estabelecidas. Ressaltamos que tal discurso foi construído com vários depoimentos reunidos num só discurso-síntese, como se um grupo falasse na primeira pessoa do singular. Os resultados apresentamos a seguir.

\section{RESULTADOS E DISCUSSÃO}

Caracterização dos sujeitos

A idade das gestantes participantes do estudo variou entre 22 e 42 anos, e todas estavam no terceiro trimestre de gestação. Mais de dois terços das entrevistadas estava na segunda ou terceira gestação, e metade delas tinha até quatro anos de aprovação escolar, incluindo três mulheres que nunca haviam freqüentado a escola. Predominantemente, não exerciam atividade remunerada, pois tratava-se, na maior parte dos casos, de donas de casa. Entre as mulheres que desenvolviam algum trabalho fora do lar, foram citadas profissões como cozinheira, empregada doméstica, costureira, comerciante e atendente de enfermagem. Apenas uma gestante disse não ter companheiro no momento da entrevista.

O discurso do sujeito coletivo

Sabe-se que a gravidez, para todas as mulheres, constitui um período de mudanças físicas e psicológicas, ansiedades, fantasias, temores e expectativas ${ }^{(2)}$. A isso pode somar-se a instauração ou o agravamento de alguma doença, surgindo, então, a "gravidez de risco", fazendo com que a mulher conviva com os mais diversos sentimentos ${ }^{(8)}$. Esse processo gestacional caracterizase por ser extremamente complexo e diversificado, sendo essencial, portanto, quando se presta o cuidado à gestante com complicações, compreendê-la em sua totalidade ${ }^{(9)}$.

Dessa maneira, o cuidado não deve ser limitado apenas aos aspectos fisiopatológicos, sendo necessário um atendimento multiprofissional, para melhor conceituar, definir parâmetros, realizar procedimentos e estabelecer medidas preventivas relativas à gravidez de alto risco ${ }^{(10)}$.

Nesta investigação, em relação ao sentimento das mulheres no momento em que souberam que estavam grávidas, a análise dos discursos permitiu-nos identificar seu contentamento, visto que a gravidez havia sido desejada, lamentando apenas a ocorrência do diabetes:

É gostoso estar grávida. Eu fiquei contente, me senti bem, porque eu queria, só que eu estaria mais feliz ainda se não tivesse diabete. Eu queria ter outro, um molequinho, aí deu o que eu queria: hoje eu fiz ultra-som e é menino, estou mais feliz ainda (DSC 1 Idéia Central 1- Felicidade frente a uma gravidez desejada).

Por outro lado, algumas mulheres relataram um sentimento de desgosto, uma vez que teriam que se privar de comer doces, por exemplo, em função da doença. Além disso, mostraram-se apreensivas com as possíveis complicações, tanto para elas quanto para seus bebês. Esse achado corrobora com a literatura, pois estudo com um grupo de gestantes de alto risco apontou como principais temores das gestantes aqueles relacionados à doença e ao bebê ${ }^{(8)}$. Vários autores argumentam que 
existem fatores físicos e emocionais que influenciam as modificações psicoafetivas da gestante e, assim, são comuns os receios relativos ao parto e estado do bebê ao nascer, de perdas e malformações, prematuridade, enfim, de que a gestação não alcance um bom resultado. Esses sentimentos entre as gestantes de risco podem estar exacerbados ${ }^{(8-9)}$, o que pudemos evidenciar no seguinte discurso:

Eu não sei explicar direito, mas minha sensação não foi agradável, pois seria preciso deixar de comer muita coisa, açúcar, essas coisas todas que eu gosto e não poderia comer mais. Além disso, eu fiquei nervosa, bastante nervosa, porque eu sabia que era perigoso dar problema para mim e para criança, que teria que fazer tratamento, pois a gravidez é de alto-risco, é uma gravidez complicada. Então, eu fiquei, preocupada, triste, principalmente por causa do nenê, eu achava que ele também ia ter diabete, que podia nascer com hipoglicemia e tinha também o medo de não ser uma criança perfeita, de ter problema (DSC 2 - Idéia Central 2 Preocupação com a gravidez e renúncia).

A respeito do planejamento da gestação, algumas a programaram junto a seus maridos (DSC 3), enquanto outras engravidaram de maneira não prevista, alegando terem, anteriormente, outros planos, como o trabalho ou a reforma da casa (DSC 4).

Eu queria ficar grávida, não foi por acaso, eu estava me sentindo muito sozinha. Aí, a gente planejou, eu e meu marido, e agora eu fiquei (DSC 3 - Idéia Central 3 - Minha gravidez foi planejada).

Eu fiquei grávida por acaso, meu plano era outro, eu ia trabalhar, planejava reformar minha casa e tive que parar, porque no começo gastava muito dinheiro com remédio e agora vem o bebê, tem que comprar o enxoval. Eu estava me cuidando, mas não tive sorte, aconteceu, aconteceu mesmo. Quando eu vi ... grávida! Foi porque Deus quis, vamos falar assim, pois quando a gente, você sabe, não tem muitas condições de vida ... Eu até fui na psicóloga e ela me deu um monte de conselho, a "amigaiada" também falava pra mim que é melhor um filho que uma doença. Aí, isso "encaixou"... se não, estaria incomodando ainda. É, eu não queria mais filho, até agora não pus meu pé no chão, mas depois que veio, né? (DSC 4 Idéia Central 4 - Meu plano era outro).

O fenômeno da gravidez não planejada é freqüente, podendo ocorrer em mulheres de diferentes faixas etárias e escolaridade. Porém, o fato de a gestação não ser programada não implica, necessariamente, crianças não desejadas. Muitas são rapidamente aceitas ou transformam-se em desejadas ao longo da gestação, resultando em situações felizes e equilibradas ${ }^{(12)}$.
Entretanto, no presente estudo, identificamos apenas um certo conformismo com a situação:

...É, eu não queria mais filho, até agora não pus meu pé no chão, mas depois que veio, né? (DSC 4).

Quando indagamos como as gestantes estavam passando na gravidez atual, algumas ponderaram que seus sinais e sintomas eram próprios da gestação:

Só sinto essas coisas que mulher grávida sente, mas é normal: um pouco de fraqueza, cansaço, inchaço, um calor, enjôo, peso do bebê, a barriga endurece, não dá pra andar direito, não dá pra fazer nada direito. Agora, no fim, a dor está demais, não consigo nem andar dentro de casa: dói as costas, a barriga, as pernas, dá cãimbra em baixo da barriga. É, agora que está perto, eu sinto muita dor, chega a travar as pernas. Mas é só isso, nada assim que eu me assustasse (DSC 5 - Idéia Central 5 - Sinto o que mulheres grávidas sentem).

Por outro lado, outras se mostraram angustiadas, queixaram-se de seus sintomas e da necessidade de internações durante a gestação, o que estaria ocasionando certo afastamento dos demais filhos.

Fato semelhante vem sendo relatado em outros estudos realizados com gestantes de risco. O controle de determinadas patologias ou sintomas associados à gravidez implica cuidados específicos por parte da gestante e da equipe de saúde, levando, inclusive, a longos períodos de internação, também responsáveis pelo estresse da paciente e de sua família. Deve-se lembrar, ainda, que, durante sua ausência decorrente de internações, as dificuldades que têm em seu lar podem continuar a existir e, assim, ocorrer certa desestruturação familiar ${ }^{(8)}$. O discurso a seguir retrata essa situação:

Desde os três meses que eu passo apertado: tive sangramento, começo de aborto, depois veio pressão alta e agora diabetes. Se eu como doce, por exemplo, eu já sinto que incho toda, formiga as mãos, dá calor e agora, no finalzinho, eu comecei a ter um pouco de ânsia e de hipoglicemia. Além disso, eu passei nervoso porque tinha que tá vindo sempre pra cá e aí, a gente que tem mais filhos, sempre acontece de ficar nervoso com isso. Eu ficava chorando, querendo ir embora, sempre meio escondido para ninguém ver, passei toda gravidez assustada, achando tudo novo, ansiosa, sempre muito agitada, nunca calma. É, eu só vou ficar feliz a hora que minha filha nascer, a hora que eu ver ela (DSC 6 - Idéia Central 6 - Tive muitos problemas na gravidez).

No tocante à maneira como os companheiros encararam a gravidez de suas esposas, alguns, assim como o restante da família, manifestaram seu contentamento (DSC 7), enquanto outros não, além de 
apresentarem preocupações referentes a eventuais complicações no momento do parto e a problemas financeiros (DSC 8).

A vivência da gestação de alto risco é uma experiência única, que se estende ao companheiro, família e sociedade ${ }^{(9)}$. É importante lembrar que a falta de suporte de pessoas significativas, como do esposo ou da família, também predispõe a depressão em gestantes ${ }^{(11)}$. Em estudo sobre o apoio que gestantes adolescentes receberam durante a gravidez, evidenciou-se que, segundo elas, o suporte familiar era composto por explicações, conselhos, carinho, apoio moral e ajuda financeira ${ }^{(13)}$.

Ele tá felicíssimo, babando, não vê a hora que o nenê nasce para ver a carinha dele. Ele queria mais que eu mesma esta gravidez, então, pra ele representa tudo que ele queria: um filho. Não é só ele não, a família inteira, meus parentes, todos estão assim (DSC 7 - Idéia Central 7 - Um filho é tudo o que ele queria).

$A h$, foi normal. Ele não teve aquela emoção, que nem mulher. Ele ficava preocupado, mais com a diabetes, com medo de prejudicar o nenê e falava pra mim fazer o regime, fazia medo em mim: olha o açúcar, olha isso, olha aquilo. Como ele tinha medo, ele pegava muito no meu pé, dizendo que se não tratar direito pode até morrer na hora do parto. Havia também outras preocupações: mais um filho, como é que vai ser pra dar saúde pra essa criança e além disso a gente precisava de uma comida especial e ele ficou muito tempo desempregado ... (DSC 8 - Idéia Central 8 - Ele não teve aquela emoção que nem mulher).

Embora não constasse da entrevista nenhuma pergunta especificamente sobre o tratamento, esse assunto surgiu espontaneamente, especialmente abordando o controle dietético. Um grupo de mulheres encarou-o sem maiores dificuldades, a fim de evitar complicações para si e para seu bebê (DSC 9), ao passo que outro grupo revelou estar sendo árduo tal controle e cometendo, algumas vezes, deslizes em relação a ele (DSC 10). Nem sempre a paciente é capaz de compreender as implicações de sua doença e a importância de sua participação ativa no tratamento, seguindo as orientações relacionadas às restrições alimentares. Assim, é freqüente o descuido alimentar em momentos de estresse ou, paradoxalmente, de melhor compensação ${ }^{(14)}$.

\section{REFERÊNCIAS BIBLIOGRÁFICAS}

1. Aquino MMA, Pereira BG, Amaral E, Parpinelli MA. Revendo diabetes e gravidez. Rev Ciênc Méd 2003 janeiro; 12(1):99106.

2. Buchabqui JA, Abeche AM, Brietzke E. Assistência pré-natal. In: Freitas F, Martins-Costa, SH, Ramos JGL, Magalhães JÁ. Rotinas em Obstetrícia. 4. ed. Porto Alegre (RS): Artmed; 2002. p.23-37.
Eu tinha medo do nenê nascer com problema, mas o médico disse que não tem tanto perigo, se eu fizer as coisas que eles mandam. Então, eu estou controlando, fazendo do jeito que eles mandam, para o nenê não nascer doente e ele (marido) ajuda. Se a gente não fazer é pior pra gente mesmo e para o nenê. Então, eu faço dieta, tomo insulina, o que eu pudé fazê eu faço pelo bebê, porque eu tô consciente que não é só eu e eu quero que ele nasça saudável (DSC 9 - Idéia Central 9 - Eu estou controlando, fazendo tudo o que o médico diz).

Depois que apareceu a diabete, eu fiquei com medo, porque eu tinha que fazer regime e não conseguia fazer direito, falavam que o nenê ia nascer grande. Agora, eu tô tentando fazer dieta, mas é difícil, eu tô me controlando, fazendo o melhor que posso, mas é muito pouco o que a gente pode comer, então, às vezes, a gente sai fora, pega coisa doce, porque a gente fica com vontade. Mas também não é nada exagerado, só uma pinicadinha pro nenê... Mulher grávida tudo o que come é o nenê(DSC 10 - Idéia Central 10 - Eu tô tentando fazer dieta, mas é difícil).

\section{CONSIDERAÇÕES FINAIS}

Analisando os discursos das gestantes diabéticas, observamos que a preocupação com o bem estar da criança esteve presente ao longo deles, muitas vezes com referência ao pai do bebê, explicitando que ele também tinha tal preocupação.

Algumas gestantes entrevistadas planejaram sua gravidez e puderam contar com o apoio do marido e familiares. Essas gestantes enfrentaram o tratamento de forma tranqüila, minimizando os sintomas desagradáveis apresentados, considerando-os próprios da gravidez. Planejar e desejar a gravidez foram essenciais para que esse evento fosse vivido de forma prazerosa, e tal fato marcou, de forma decisiva, o significado da gestação para essas mulheres.

Outras gestantes, porém, não haviam planejado a gravidez, e a participação dos maridos foi menor. Para essas, a gestação significou algo incômodo, que as obrigava a seguirem um tratamento difícil, principalmente devido à necessidade de controle dietético.

3. Maganha CA, Bernardini MA, Vanni DGBS, Nomura RMY, Zugaib M. Repercussões do diabetes no feto e recémnascido. Rev Ginecol Obstet 2002 julho; 13(3):158-62.

4. Silva MRG, Calderon IMP, Gonçalves LC, Aragon FF, Padovani CR, Pimenta WP. Ocorrência de diabetes melito em mulheres com hiperglicemia em gestação prévia. Rev Saúde Pública 2003 junho; 37(3):345-50.

5. Minayo MCS. Ciência, técnica e arte: o desafio da pesquisa social. In: Minayo MCS, organizadora. Pesquisa social: teoria, método e criatividade. Petrópolis (RJ): Vozes; 1994. p. 9-29. 
6. Triviños ANS. Introdução à pesquisa em ciências sociais: a pesquisa qualitativa em educação. São Paulo (SP): Atlas; 1992.

7. Lefèvre F, Lefèvre AMC, Teixeira JJV, organizadores. O discurso do sujeito coletivo: uma nova abordagem metodológica em pesquisa qualitativa. Caxias do Sul (RS): Educs; 2000.

8. Araujo A, Quayle J, Kahhale S, Souza MC. Um estudo sobre gestantes hipertensas e adesão ao tratamento médico: abordagem descritiva. Rev Ginecol Obstet 1998 outubro; 9(4):191-8.

9. Zampieri MFM. Vivenciando o processo educativo em enfermagem com gestantes de alto risco e seus acompanhantes. Rev Gauch Enfermagem 2001 janeiro; 22(1):140-66.

10. Gomes R, Cavalcanti LF, Marinho ASN, Silva LGP. Os sentidos do risco na gravidez segundo a obstetrícia: um estudo bibliográfico. Rev Latino-am Enfermagem 2001 julho; 9(4):62-7.

11. Jadresic E, Jara C, Araya R. Depresión en el embarazo y en el puerpério: estudio de factores de riesgo. Acta Psiquiátr Psicol Am Lat 1992 marzo; 39(1):63-74.

12. Silva JLP. Gravidez na adolescência: desejada $X$ não desejada. Femina 1998 novembro; 26(10):825-30.

13. Godinho RA, Schelp JRB, Parada CMGL, Bertoncello NMF. Adolescentes e grávidas: onde buscam apoio? Rev Latinoam Enfermagem 2000 abril; 8(2):25-32.

14. Quayle J, Nascimento R, Kahhale S, Sabbaga E, Neder $\mathrm{M}$, Zugaib $\mathrm{M}$. Fantasias associadas à maternidade entre mulheres em tratamento dialítico: abordagem qualitativa. Rev Ginecol Obstet 1998 abril; 9(2):56-60. 